\title{
INTERPRETANDO TEXTOS ORGANIZACIONAIS: UM ENFOQUE METODOLÓGICO PARA A APLICAÇÃO DE UMA HERMENÊUTICA FENOMENOLÓGICA DE TEXTOS DE ESTRATÉGIA
}

\author{
INTERPRETING ORGANIZATIONAL TEXTS: \\ A METHODOLOGICAL FOCUS ON THE APPLICATION OF \\ HERMENEUTIC PHENOMENOLOGY TO STRATEGY TEXTS
}

\section{NOBUIUKI COSTA ITO nobuiuki@usp.br UNIVERSIDADE DE SÃO PAULO \\ FERNANDO ANTONIO PRADO GIMENEZ UNIVERSIDADE FEDERAL DO PARANÁ}

RESUMO

O campo dos Estudos Organizacionais é fragmentado, dicotômico e plural. Essas características formam campos de estudos com diferentes teorias e escolas de pensamento, que têm um mesmo objeto, mas que utilizam pressupostos, muitas vezes, antagônicos e mutuamente excludentes. O objetivo do artigo é propor um framework hermenêutico, que utiliza uma abordagem fenomenológica, a ser aplicado na interpretação de textos organizacionais de um mesmo campo independentemente de pressupostos conflitantes, utilizando a aplicação na Estratégia como um exemplo. Hermenêutico porque lida somente com a interpretação de textos; e fenomenológico porque oferece caminhos para uma interpretação subjetiva do pesquisador. A interpretação dos textos sob o novo olhar proposto distingue-se do método fenomenológico dos Estudos Organizacionais por ter as teorias como objeto de análise e não a realidade empírica. Essa interpretação é intuitiva e recebe influência das crenças do pesquisador e, por isso, deve ser fruto do emprego rigoroso de um método: (I) seleção das obras; (2) leitura e geração de protocolos; (3) redução fenomenológica, transformando os protocolos em temas; e (4) análise estrutural do fenômeno. Para ilustrar os passos é apresentada uma análise de textos de Porter e da Teoria Baseada em Recursos.

Palavras-chave: hermenêutica; fenomenologia; método.

\section{ABSTRACT}

The field of Organizational Studies is fragmented, dichotomous and plural. These characteristics have given rise to approaches with different theories and schools of thought with the same object, but relying on assumptions and foundations that often clash and are mutually exclusive. The purpose of this paper is to present a hermeneutical framework using a phenomenological approach that can be used to interpret organizational texts from the same field, in this case, Strategy, independently of conflicting assumptions. It is hermeneutical because it deals solely with the interpretation of texts, and phenomenological because of the subjective interpretation of the researcher. While Organizational Studies approaches phenomenology through empirical reality, this proposed framework focuses on the object of analysis. The interpretation is intuitive and loaded with the researcher's beliefs and convictions and should, therefore, be the result of a strict methodology: (1) text selection; (2) reading the texts and drawing up protocols; (3) phenomenological reduction, turning the protocols into themes; and (4) structural analysis of the phenomenon. Texts by Porter on Resource-based Theory were used to illustrate each step.

Keywords: hermeneutics, phenomenology; method. 


\section{INTRODUÇÃO}

A pesquisa em Estudos Organizacionais, vez por outra, é palco de disputas entre diferentes perspectivas. Talvez, por um lado, essa característica mais belicosa esteja relacionada a uma fase pré-paradigmática (кUHN, 2000), em que várias correntes de pensamentos concorrentes surgem e disputam a predominância. Ou, por outro lado, essa é uma característica inerente ao fenômeno social, em que apenas uma faceta não é capaz de representar a complexidade das relações humanas, tornando o campo difuso. De uma maneira ou de outra, pode-se encontrar um campo de estudos com inúmeras abordagens, tais como: Teoria da Contingência Estrutural, Ecologia Organizacional, Teoria Institucional, Teoria Crítica, entre outras. Essas diferentes abordagens encontram fundamentos teóricos em diversos campos, como, por exemplo, a Economia, a Sociologia, a Psicologia, as Ciências Biológicas, a História e a Filosofia.

Esse esforço para entender as organizações é um movimento científico mais recente, quando comparado ao esforço das Ciências Naturais e, nesse percurso, não há dúvidas de que a ciência como "tradicionalmente" reconhecida está relacionada, primordialmente, com as ditas "Ciências Naturais". Muito do esforço das Ciências Sociais, onde se inserem os Estudos Organizacionais, concentra-se em transportar os métodos e padrões da pesquisa tradicional para a construção da teoria social. Esse esforço esbarra em algumas inconsistências, pois "as possíveis variedades de escolhas [nas Ciências Sociais] são na verdade tão grandes que o que é considerado como ciência pelo cientista tradicional abrange apenas uma pequena variedade de opções" (BURRel; MORGan, 1979, p. 2) . Assim, podem ser encontrados trabalhos em Estudos Organizacionais que assumem a realidade em qualquer ponto de um continuum cujos extremos apresentam a realidade como natural, dada e concreta e a realidade como subjetivamente construída.

O entendimento dos fenômenos sociais envolve o entendimento das ações humanas, que dificilmente é identificado por uma abordagem positivista $\mathrm{e}$ exteriormente observável. O fenômeno social é ambivalente, complexo e contraditório, o que, invariavelmente, constitui diferentes teorias e escolas 
de pensamento que compõem um mesmo campo de estudo, com mesmo objeto, mas com pressupostos e fundamentos antagônicos e mutuamente excludentes. Ademais, definir o objeto de estudo de determinado campo não é tão claro e direto: qual o objeto de estudo da Administração, por exemplo? Dadas essas características, a tarefa de conduzir discussões teóricas e escrever ensaios teóricos no campo dos Estudos Organizacionais é um desafio, pois a coleção de visões diferentes sobre um mesmo assunto pode dificultar ou tornar confusa a interpretação e análise dos textos. O que se argumenta é que a análise de textos organizacionais é tão complicada quanto a investigação empírica, o que demanda cuidados do pesquisador.

Tendo esse problema em vista, esse artigo propõe construir um framework para a interpretação de textos capaz de explorar um objeto de estudo sem as amarras oferecidas por pressupostos teóricos conflitantes de correntes de pensamento concorrentes, na tentativa de trazer à luz a essência do fenômeno estudado. Tal interpretação não é trivial como pode parecer à primeira vista, devido à incompatibilidade de pressupostos que duas correntes de pensamento de um mesmo campo podem oferecer. $\mathrm{O}$ framework busca na Fenomenologia os fundamentos para a interpretação, pois a própria fenomenologia constitui um método para a investigação das essências. A interpretação dos textos sob o novo olhar proposto distingue-se do método fenomenológico dos Estudos Organizacionais por ter as teorias como objeto de análise e não a realidade empírica, como será discutida posteriormente. Além disso, pode ser visto como um exercício propedêutico para uma pesquisa, ou seja, é um passo anterior à execução da pesquisa propriamente dita, que pode abrir os olhos do pesquisador para assuntos que poderiam ser desconsiderados a priori.

O objetivo do artigo, portanto, é propor um framework hermenêutico que utiliza uma abordagem fenomenológica a ser aplicado na interpretação de textos organizacionais de um mesmo campo independentemente de pressupostos conflitantes, utilizando a literatura da Administração Estratégica como um exemplo. Os Modelos de Michael E. Porter e a Teoria Baseada em Recursos têm importante impacto na literatura em Administração Estratégica (RAMOS-RODRíGUEZ; RUÍZ-NAVARRO, 2004) e ambas 
possuem raízes na Economia, entretanto, com pressupostos teóricos conflitantes. Ao se analisarem os textos dessa literatura, utilizando o procedimento proposto, o pesquisador é estimulado a deixar as lentes teóricas diferentes de lado e visualizar aquilo que não varia entre as diferentes perspectivas. Essa atitude pode ajudar a enxergar aspectos que são essenciais para seu estudo, oferecendo uma amplitude de opções maior para o desenvolvimento do trabalho.

O artigo está organizado em quatro seções, incluindo esta seção inicial. Antes da apresentação do framework proposto, na próxima seção, algumas ideias fundamentais são descritas e explicadas, especialmente sobre a hermenêutica, de forma geral, e a hermenêutica fenomenológica, de forma particular. A seção três constrói uma sequência de ações a serem aplicadas na interpretação de textos, seguindo o framework hermenêutico fenomenológico, constituindo um conjunto de princípios e tarefas que almejam identificar os temas estruturais do objeto estudado, utilizando, para isso, a análise dos textos da literatura de Administração Estratégica. Por fim, a seção quatro apresenta as considerações finais. 


\section{A HERMENÊUTICA E SUA ABORDAGEM FENOMENOLÓGICA}

Definir a hermenêutica não é tarefa simples. No senso comum, pode-se definir a hermenêutica como interpretação do sentido das palavras (ou dos textos sagrados). Comumente é encontrada, também, a definição de hermenêutica como uma arte; a arte da interpretação de textos. Em uma ordem cronológica pouco rigorosa, apresentada por Palmer (1997), a hermenêutica tem sido compreendida como:

I) uma teoria da exegese bíblica; 2) uma metodologia filológica geral; 3) uma ciência de toda compreensão linguística; 4) uma base metodológica dos Geisteswissenschaften; 5) uma fenomenologia da existência e da compreensão recolectivos e iconoclásticos, utilizados pelo homem para alcançar o significado subjacente aos mitos e símbolos (PALMER, 1997, p. 43).

O mais antigo e talvez mais difundido entendimento de hermenêutica é o da interpretação bíblica, utilizada desde o século xvir. Entretanto, a partir do século xviII, a hermenêutica passou a ser referida como modo de tratamento da compreensão de textos não bíblicos, com caráter filológico. Ocorre, então, uma primeira ruptura, fruto de uma crítica radical do ponto de vista filológico, quando a hermenêutica deixa de ser tratada como uma disciplina, e passa a ser um estudo da própria compreensão, "cujos princípios possam servir de base a todos os tipos de interpretação de texto" (PALMER, 1997, p. 50).

Um segundo ponto de virada foi uma abordagem da hermenêutica de uma explicação fenomenológica da própria existência humana, "com a controversa afirmação de Gadamer de que «um ser que pode ser compreendido é linguagem» a hermenêutica é um encontro com o Ser por meio da linguagem" (PALMER, 1997, p. 52). Nesse sentido, a hermenêutica se preocupa em como ocorre a compreensão, como ocorre a desocultação ou clarificação do que está no texto. A preocupação deixa de ser a compreensão correta, mas como ocorre a própria compreensão.

Considerando essa evolução da hermenêutica e, também, suas diversas aplicações nas pesquisas em Ciências Sociais, o que se identifica são três abordagens diferentes. A primeira define hermenêutica como um método 
objetivo de interpretação, denominada de abordagem objetivista. Dentro da abordagem objetivista, autores como Shleiermacher e Dilthey defendem que a hermenêutica é um conjunto de princípios metodológicos que subjazem à interpretação. Emilio Betti foi um dos principais filósofos da tradição objetivista, pois procurou oferecer uma teoria geral da hermenêutica, estabelecendo regras de interpretação que garantem a objetividade e validade. Dessa forma, a hermenêutica seria capaz de fornecer a "interpretação correta" ou "o sentido exato" do texto.

A segunda abordagem utiliza a hermenêutica como análise do discurso, podendo ser encontrados fundamentos na Psicanálise (GODOI, 2006; VRIES; MILLER, 1987) ou na Linguística (FAIRCLOUGH, I992). Nessa abordagem, a hermenêutica é utilizada para desvendar aspectos ocultos no texto e que possam indicar as explicações de mudanças sociais ou que ajudem aos pesquisadores a reconhecer pressupostos e orientações cruciais das pessoas, que são alvos de investigação e que irão influenciar nos aspectos organizacionais, tais como cultura, estratégia ou estrutura.

Por fim, uma terceira abordagem da hermenêutica é caracterizada por uma exploração filosófica. A abordagem é influenciada primordialmente pela Fenomenologia (Husserl, 2002) e é desenvolvida por Heidegger (1986) e Gadamer, denominada de hermenêutica fenomenológica. A hermenêutica fenomenológica busca encontrar o sentido do ser na linguagem, ou seja, explora a hermenêutica "em seu elemento puro de experiência da existência humana. [...] Por isso GADAMER vai dizer [...] que a compreensão pertence ao ser que se compreende" (SPAREMberger, 2003, p. I84). Nesse sentido, a compreensão transforma-se em uma tarefa ontológica de apreender o sentido do ser dos entes, chegando a conceitos essenciais anteriores ao conhecimento empírico, não pela indução ou dedução, mas por pura intuição.

As abordagens da hermenêutica podem ser identificadas pelo Quadro I: 
Quadro 1 As abordagens da Hermenêutica

\begin{tabular}{|lll|}
\hline Abordagem Objetivista & $\begin{array}{l}\text { Abordagem da Análise do } \\
\text { Discurso }\end{array}$ & $\begin{array}{l}\text { Abordagem } \\
\text { Fenomenológica }\end{array}$ \\
\hline Betti & Fairclough & Heidegger \\
Dilthey & Godoi & Gadamer \\
Schleiermacher & Vries e Miller & \\
\hline
\end{tabular}

As abordagens da hermenêutica podem ter diferentes aplicações nas pesquisas organizacionais. Para a metodologia construída nesse artigo, a hermenêutica fenomenológica é considerada capaz de envolver em um só momento uma pluralidade de perspectivas, pois está diretamente concentrada no desvelamento daquilo que essencialmente é o objeto de estudo. 


\section{HERMENÊUTICA FENOMENOLÓGICA}

Utilizando fundamentos da fenomenologia, a hermenêutica ocupa-se da desocultação ou desvelamento daquilo que está essencialmente no texto. Mas o que é fenomenologia? "A expressão 'fenomenologia' diz, antes de tudo, um conceito de método" (HEIDEGGeR, 1986, p. 57). A Fenomenologia é um importante movimento filosófico que nasce no início do século XX, com a publicação das primeiras Investigações Lógicas de Edmund Husserl. Martin Heidegger foi aluno de Husserl e desenvolveu suas investigações com forte influência das obras e ideias de seu professor (HISTÓRIA DA FILOSOFIA, I98I).

Heidegger (1986) explica que o termo Fenomenologia é formado por duas palavras: fenômeno e logos. O termo fenômeno remonta à palavra grega phaenesthai, que significa aquilo que se mostra; aquilo que se revela. Avançando um pouco mais neste conceito, o fenômeno é construído com base em phaino, que quer dizer trazer à luz do dia, clarificar. Assim, o sentido aqui atribuído ao fenômeno nada tem a ver com o sentido vulgar do termo, que está mais relacionado à manifestação. "É muito corrente falar-se de manifestações de uma doença. O que se tem em mente são ocorrências que se manifestam no organismo e, ao se manifestarem, 'indicam' algo que em si não se mostra” (HEIDEGGER, 1986, p. 59). Dessa forma, o fenômeno não é necessariamente uma manifestação, mas toda manifestação depende de um fenômeno. Apesar de Heidegger (1986) se aprofundar nessa discussão, para a análise a ser desenvolvida no artigo, esta distinção é suficiente, destacando que o fenômeno para Fenomenologia é aquilo que se mostra em si mesmo.

Outro conceito discutido detidamente por Heidegger (1986) é o conceito de logos. Também não é necessário prolongar-se nessa questão, mas esclarecer que a função do logos "reside num puro deixar e fazer ver, deixar e fazer perceber o ente" (HEIDEGGER, 1986, p. 64). Essas conceituações anteriores permitem oferecer o sentido adotado para Fenomenologia como "deixar e fazer ver por si mesmo aquilo que se mostra, tal como se mostra a partir de si mesmo" (HEIDEGGER, 1986, p. 65). 
O termo fenomenologia tem, portanto, um sentido diferente das designações como teologia etc. Estas evocam os objetos de suas respectivas ciências, em seu conteúdo quididativo. O termo 'fenomenologia' nem evoca o objeto de suas pesquisas nem caracteriza seu conteúdo quididativo. A palavra se refere exclusivamente ao modo como se de-monstra e se trata o que nesta ciência deve ser tratado (HEIDEGGER, I986, p. 65, negrito adicionado) .

Agora as palavras de Heidegger (I986), ao afirmar que a Fenomenologia é antes de tudo um método, podem ser compreendidas, já que a Fenomenologia, na verdade, não é uma ciência de um objeto específico, mas um modo de tratamento do que está sendo estudado, como, por exemplo, uma Fenomenologia da Estratégia. Heidegger (1986) utiliza a Fenomenologia como método para responder à questão do sentido do ser dos entes, ou seja, como um caminho para a questão do ser. Ao desenvolver seus esclarecimentos iniciais acerca da questão do ser, Heidegger (I986) afirma que aquilo que deve se tornar fenômeno pode se encobrir de diversos modos, esclarecendo que:

É por isso também que o ponto de partida das análises, o acesso aos fenômenos e a passagem pelos encobrimentos vigentes exigem uma segurança metódica particular. A ideia de apreensão e explicação 'originárias' e 'intuitivas' dos fenômenos abriga o contrário da ingenuidade de uma 'visão' casual, 'imediata' e impensada (HEIDEGGER, 1986, p. 67, itálico no original).

Essa segurança metódica é fornecida pela Fenomenologia, que se apresenta como a ciência do ser dos entes. "A fenomenologia é a via de acesso e o modo de verificação para se determinar o que deve constituir tema da ontologia. A ontologia só é possivel como fenomenologia" (HEIDEGGER, I986, p. 66, itálico no original). E somente a ontologia pode se colocar diante da questão sobre o sentido do ser. Nesse sentido, Heidegger (I986) afirma que

Da própria investigação resulta que o sentido metódico da descrição fenomenológica é interpretação. [...] Fenomenologia da pre-sença é hermenêutica no sentido originário da palavra em que se designa o ofício de interpretar. Na medida, porém, em que se desvendam o sentido do ser e as estruturas fundamentais da pre-sença em geral, abre-se o horizonte para qualquer investigação ontológica ulterior dos entes não dotados de 
caráter na pre-sença. A hermenêutica da pre-sença torna-se também uma 'hermenêutica' no sentido de elaboração das condições de possibilidade de toda a investigação ontológica (HEIDEGGER, 1986, p. 68-9, itálico no original). Heidegger (1986) utiliza a fenomenologia para tentar desvendar o sentido do ser da pre-sença. A pre-sença

Não é sinônimo nem de homem, nem de ser humano, nem de humanidade, embora conserve uma relação estrutural. Evoca o processo de constituição ontológica de homem, ser humano e humanidade. É na presença que o homem constrói o seu modo de ser, a sua existência, a sua história etc. (HEIDEGGER, 1986, p. 309).

Apesar de sua investigação ter foco delimitado no sentido da pre-sença, Heidegger (1986) abre espaço para a utilização da Fenomenologia como uma hermenêutica para elaboração de investigações ontológicas de qualquer ente, mesmo daqueles não dotados de caráter na pre-sença. Assim, a Fenomenologia é um método que reúne capacidades para investigações do sentido do ser dos entes, pois constitui uma ciência das ciências. A aplicação da Fenomenologia está na busca ontológica do sentido do ser, ou seja, sua essência.

Assim, pesquisas no campo dos Estudos Organizacionais utilizam a fenomenologia na busca de compreender os significados da experiência vivida (SILVA, 2006), ou seja, tentam compreender as percepções subjetivas do fenômeno social. Essas pesquisas desvendam a realidade empírica pela interpretação de textos ou alguma forma simbólica. Com efeito, as investigações empíricas com o método fenomenológico utilizam-se da hermenêutica como um método de interpretação do fenômeno vivido subjetivamente pelo ator social. Para isso, técnicas de geração de protocolos e fichamentos foram desenvolvidas, a fim de identificar aspectos essenciais da descrição oferecida pelos atores (MOUSTAKAS; 1994; MOREIRA, 2002).

Entretanto, outro desafio encarado por pesquisadores dos Estudos Organizacionais é a elaboração de ensaios e discussões teóricas, em que o rigor e disciplina na análise e interpretação se fazem necessários, frente à multiplicidade de perspectivas e aos backgrounds teóricos do campo. O que está sendo interpretado, em uma discussão teórica, muitas vezes não é a 
realidade, mas a abstração da realidade incutida em pressupostos, fatores e relações entre fatores, reunidos em uma teoria. A interpretação não é da realidade como experienciada pelo ator, mas dos pontos essenciais do fenômeno, que aparece em diferentes visões, sintetizados em argumentos e afirmações teóricas. O que se pretende nesse artigo, portanto, é oferecer uma alternativa metodológica para interpretação de textos que, embora tenha técnicas e métodos inspirados no método fenomenológico tradicionais dos Estudos Organizacionais, é endereçada a um objeto distinto: a teoria - abstração da realidade. A fenomenologia de textos organizacionais, em que a interpretação subjetiva do pesquisador é posta em prova, necessita de uma linha guia dentro do mundo multifacetado e antagônico das teorias organizacionais. 


\section{PROPOSTA DE UM FRAMEWORK INTERPRETATIVO DE TEXTOS ORGANIZACIONAIS: PORTER E A VISÃO BASEADA EM RECURSOS}

A proposta é oferecer um framework interpretativo para textos organizacionais. Esse é um framework hermenêutico fenomenológico. Hermenêutico porque lida somente com a interpretação de textos e fenomenológico porque oferece caminhos para uma interpretação subjetiva do pesquisador. Nesse sentido, o pesquisador encontra o seu sentido de Estratégia baseado na leitura de seus textos e torna isso concreto ao escrever seus significados e relações que serão traduzidos em estruturas do fenômeno.

A Fenomenologia é uma ciência que partiria do "zero", sem qualquer pressuposição, o que Husserl chama de Epoche. Epoche é um termo grego que significa abster-se ou "ficar de fora", ou seja, requer o afastamento das pressuposições, dos conhecimentos anteriores, do dia a- dia, do modo convencional de olhar um determinado assunto.

Husserl [...] contrastou a Epoche fenomenológica universal com a dúvida cartesiana. A Epoche fenomenológica não elimina tudo [...]. O que é duvidado são os 'fatos' científicos, o saber das coisas com antecedência, a partir de uma base externa, ao invés de partir de uma reflexão interna e do significado (MOUSTAKAS, I994, p. 85) .

O fato de duvidar do que é externo ou dos fatos "consagrados" pela ciência não quer dizer que a Fenomenologia nega o mundo, mas que apenas não se prende ao que é real, tomando o mundo simplesmente o que ele é para a consciência.

Epoche inclui a entrada em um lugar interno puro, como um ser aberto, pronto para envolver a vida no que ela realmente oferece. Pela Epoche, nós somos desafiados a criar novas ideias, novos sentimentos, novas consciências e compreensões. Nós somos desafiados a tomar conhecimento de coisas com uma receptividade e presença que nos deixam ser e deixam as situações serem, assim nós podemos conhecê-los justamente do modo que aparecem para nós. (MOUSTAKAS, 1994).

Ao atingir a Epoche, o passo seguinte da Fenomenologia é a redução fenomenológica-transcendental. 
É chamada transcendental porque se move através do cotidiano para o puro ego, em que tudo é percebido no momento, como se fosse pela primeira vez (MOUSTAKas, 1994, p. 34).

É chamado de "fenomenológica", pois ela transforma o mundo em meros fenômenos. É chamado de "redução", pois ela nos leva de volta (Lat reducere) para a fonte do significado e existência do mundo experimentado (schmitT apud moustaKas, 1994, p. 34, itálico no original) .

$\mathrm{Na}$ redução fenomenológica-transcendental todas as crenças, opiniões, tradições, doutrinas acerca da realidade e a própria realidade são colocadas entre parênteses.

Pode-se assim examinar todos os conteúdos de consciência, não para determinar se tais conteúdos são reais ou irreais, imaginários, etc., mas sim para examiná-los como puramente dados. Mediante suspensão, a consciência fenomenológica pode ater-se ao dado enquanto tal - quer seja fornecido pela percepção, intuição, recordação, quer seja pela imaginação ou julgamento - e descrevê-lo em sua pureza. Trata-se de uma atitude radical: a da suspensão do mundo natural (MOREIRA, 2002, p. 88-89).

Assim, somos capazes de transportar os objetos "da consciência de objetos individuais e concretos para o domínio transempírico das essências puras, atingindo a intuição do eidos [...] Eidos é o princípio ou estrutura necessária da coisa." (MOREIRA, 2002, p. 89). O eidos, ou a essência, é

A mesma característica do aparecer de um dado fenômeno. É aquilo que é inerente ao fenômeno, sem o que ele não é mais o mesmo fenômeno. A essência não é simplesmente o resultado de uma abstração ou comparação de vários fatos. Na verdade, no mundo natural, para podermos comparar vários fatos isolados, já é preciso ter captado uma essência, ou seja, um aspecto pelo qual se possa julgar se eles são semelhantes. O conhecimento das essências é intuição, uma intuição diferente daquela que nos permite captar fatos singulares. As essências são conceitos, isto é, objetos ideais que nos permitem distinguir e classificar os fatos (MOREIRA, 2002, p. 84)

Para alcançar essa essência é utilizado um método chamado de variação imaginativa, pois a "essência de um fenômeno é sua parcela invariável, que se conserva variando imaginativamente todos os ângulos possíveis de visão 
do fenômeno" (MOREIRA, 2002, p. II4). Este método tem a finalidade de captar a essência estrutural da experiência e consiste em variar imaginativamente um objeto em diferentes aspectos. "A Variação Imaginativa capacita o pesquisador a produzir temas estruturais das descrições textuais obtidas pelas Reduções Fenomenológicas" (MOUSTAKAS, 1994, p. 99) .

A proposta é desenvolver framework capaz de orientar a leitura de textos organizacionais sobre um mesmo objeto, mas com pressupostos teóricos conflitantes. É uma abordagem ontológica do sentido do ser de determinado ente (objeto do estudo). A fim de ilustrar o framework proposto, utilizarse-á a análise de textos de duas escolas de pensamento da Administração Estratégica, a saber: os Modelos de Michael E. Porter (PORTER, I980, 1985) e a Teoria Baseada em Recursos (tBr) (Lippman; RUMelt, 1982; RUMelt, I984; WERNERFELT, I984; DIERICKX; COOL, I989; BARNEY, I99I; PETERAF, I993). Segundo Barney (199I), enquanto Porter está fundamentado na Economia da Organização Industrial (MASON, 1939; BAIN, 1965) e tem a homogeneidade entre firmas e a mobilidade perfeita de recursos como pressupostos, a TBR emerge da insatisfação com os fundamentos da Organização Industrial, tomando pressupostos contrários, ou seja, a heterogeneidade entre firmas e mobilidade imperfeita de recursos.

Assim, trabalhar de uma forma conjunta com duas correntes de pensamento potencialmente complementares, na medida em que Porter se atém ao externo e a TBR ao interno, mas com pressupostos conflitantes é uma oportunidade para a aplicação do framework da hermenêutica fenomenológica. Essa interpretação é intuitiva e com intensa influência das convicções e crenças do pesquisador e, por isso, não deve ser imediata e casual, mas fruto do emprego rigoroso de uma sequência de ações: (I) seleção das obras; (2) leitura inicial e geração de protocolos codificados; (3) redução fenomenológica, transformando os protocolos codificados em temas; e (4) análise estrutural do fenômeno

\section{SELEÇÃO DAS OBRAS}

O passo inicial é selecionar um conjunto de textos que se interessam pelo objeto de estudo. Esta tarefa pode ser apoiada por estudos bibliométricos 
já realizados ou pela própria realização de estudos bibliométricos. Dois estudos bibliométricos apoiaram a seleção das obras do exemplo, são eles: Ramos-Rodríguez e Ruíz-Navarro (2004) e Nerur, Rasheed e Natajan (2008). Esses dois estudos bibliométricos supracitados avaliam a produção científica do campo da Administração Estratégica no período de 1980 a 2000 e permitem obter uma visão geral da pesquisa no campo, bem como da sua evolução.

Além de estudos bibliométricos, o pesquisador pode incluir textos por um critério subjetivo. Esse procedimento visa a incluir textos não considerados nos estudos bibliométricos por terem sidos publicados posteriormente à realização de tais estudos ou por serem considerados fundamentos para a interpretação dos textos selecionados pelo primeiro critério. No exemplo examinado, na perspectiva de Porter, foi adicionado um trabalho recente, Porter (1996), fora do escopo dos estudos bibliométricos e, além disso, dois estudos da Economia da Organização Industrial, o livro de Bain (1965) e o artigo de Mason (1939), pois ambos permitem a compreensão de fundamentos econômicos da Visão de Porter. O Quadro 2 relaciona os textos selecionados.

Quadro 2 Seleção inicial das obras

\begin{tabular}{|ll|}
\hline Perspectiva & Obra \\
\hline Porter & Porter (1980). Competitive Strategy. Free Press: New York. \\
& Porter (1985). Competitive Advantage. Free Press: New York. \\
& (*) Porter (1996). What is strategy? Harvard Business Review, v. 74. \\
& (*) Bain (1965). Industrial organization. John Wiley \& Sons: New York. \\
& (*) Mason (1939). Price and Production Policies of Large-Scale Enterprise. Ame- \\
& rican Economic Review.
\end{tabular}




\begin{tabular}{|c|c|}
\hline Perspectiva & Obra \\
\hline \multirow[t]{7}{*}{ TBR } & $\begin{array}{l}\text { Barney (1991). Firms resources and sustained competitive advantage. Journal } \\
\text { of Management, v. } 17 .\end{array}$ \\
\hline & $\begin{array}{l}\text { Wernerfelt (1984). A resourced-based view of the firm. Strategic Management } \\
\text { Journal, v.5, n. } 2 \text {. }\end{array}$ \\
\hline & Penrose (1959). The Theory of Growth of the Firm. Basil Blackwell: London. \\
\hline & $\begin{array}{l}\text { Peteraf (1993). The cornerstone of competitive advantage: a resource based view. } \\
\text { Strategic Management Journal, v. 14, n. } 3 \text {. }\end{array}$ \\
\hline & $\begin{array}{l}\text { Dierickx; Cool (1989). Asset stock accumulation and sustainability of competitive } \\
\text { advantage. Management Science, v. } 35 .\end{array}$ \\
\hline & $\begin{array}{l}\text { Lippman; Rumelt (1982).Uncertain imitability: an analysis of interfirm differences } \\
\text { in efficiency under competition. Bell Journal of Economics. }\end{array}$ \\
\hline & $\begin{array}{l}\text { Rumelt (1984). Towards a strategic theory of the firm. In: Competitive Strategic } \\
\text { Management, Lamb RB (ed). Prentice Hall: Englewood Cliffs. }\end{array}$ \\
\hline
\end{tabular}

$\left(^{\star}\right)$ obras selecionadas por critério subjetivo dos pesquisadores.

Os textos apresentam visões diferentes e, até mesmo, mutuamente excludentes. A hermenêutica fenomenológica, ao atingir essencialmente o objeto, deixando o que resta "entre parênteses" é capaz de informar aspectos a priori do fenômeno que podem ser negligenciados ao considerarem apenas uma perspectiva.

\section{LEITURA INICIAL E PROTOCOLOS CODIFICADOS}

Com base em uma situação em que o pesquisador tentará se aproximar da Epoche, os textos a serem interpretados são lidos e, dessa leitura, gerados protocolos codificados, contendo as transcrições dos trechos mais relevantes e o número da página que foi extraído. Para organizar os protocolos, a seguinte codificação é utilizada "A.O.n”, onde "A" identifica a perspectiva (Porter ou VBR), o "O” identifica a obra e " $\mathrm{n}$ ” identifica o número sequencial da citação. Por exemplo, utilizando as informações do Quadro 4 abaixo, pode-se extrair do protocolo da terceira transcrição da perspectiva de Porter, extraída da obra Competitive Strategy (PORTER, I980), como “P.I.3”, conforme códigos especificados no Quadro 3. 
Quadro 3 Protocolos codificados

\begin{tabular}{|c|c|c|c|}
\hline \multicolumn{2}{|c|}{ Componente "A" } & \multicolumn{2}{|l|}{ Componente "O" } \\
\hline Perspectiva & Código & Obra & Código \\
\hline \multirow[t]{3}{*}{ Porter } & \multirow[t]{3}{*}{$\mathrm{P}$} & Porter (1980) - capítulos 1, 2, 3 e 7 & 1 \\
\hline & & Porter (1985) - introdução e capítulos 1, 2, 3, 4 e 7 & II \\
\hline & & Porter (1996) & III \\
\hline \multirow[t]{7}{*}{ TBR } & \multirow[t]{7}{*}{$\mathrm{R}$} & Barney (1991) & 1 \\
\hline & & Wernerflet (1984) & II \\
\hline & & Peteraf (1993) & III \\
\hline & & Dierickx; Cool (1989) & IV \\
\hline & & Lippman; Rumelt (1982) & $\mathrm{v}$ \\
\hline & & Rumelt (1984) & VI \\
\hline & & Teece; Pisano; Shuen (1997) & VII \\
\hline
\end{tabular}

Os códigos são procedimento que visam apenas facilitar à identificação do trecho codificado. Esse procedimento permite que o autor volte ao texto em qualquer momento de sua análise. A codificação, ao lado de cada uma das transcrições, é apontada como a descrição da ideia contida no trecho, conforme a perspectiva do pesquisador. O Quadro 4 apresenta alguns exemplos de protocolos codificados, realizados durante a pesquisa. A primeira coluna apresenta o código que permite identificar a origem do texto, a coluna do meio apresenta a transcrição pura do texto da obra; este é um texto "ingênuo" ou não analisado e a coluna mais à direita apresenta a unidade de significado, que corresponde à descrição que faz sentido para o pesquisador com base no que está sendo estudado. 
Quadro 4 Protocolos codificados

\begin{tabular}{|c|c|c|}
\hline Código & Trecho literal (com página) & Unidade de significado \\
\hline (P.O.n) & Transcrição do trecho da obra (página) & $\begin{array}{l}\text { Descrição do sentido dado pelo autor do } \\
\text { trecho transcrito. }\end{array}$ \\
\hline P.I.3 & $\begin{array}{l}\text { "firms often begin with or later develop dif- } \\
\text { ferences in skills resources, and thus select } \\
\text { different strategies" (p. 135) }\end{array}$ & $\begin{array}{l}\text { Existe heterogeneidade entre firmas, } \\
\text { que ocorre pelas diferenças nas } \\
\text { capacidades/atividades }\end{array}$ \\
\hline P.I.12 & $\begin{array}{l}\text { once the forces affecting competition in } \\
\text { industry and their underlying cause have } \\
\text { been diagnosed, the firm is in position to } \\
\text { indentify its strengths and weakness rela- } \\
\text { tive to the industry }\end{array}$ & $\begin{array}{l}\text { Forças e fraquezas devem ser avaliadas } \\
\text { com base no ambiente externo. Fit }\end{array}$ \\
\hline P.II.45 & $\begin{array}{l}\text { "Value activities are therefore the discrete } \\
\text { building blocks of competitive advantage" } \\
\text { (p. 38) }\end{array}$ & $\begin{array}{l}\text { Atividades como fonte de vantagem } \\
\text { competitiva }\end{array}$ \\
\hline R.II.3 & $\begin{array}{l}\text { "In analogy to entry barriers, these are asso- } \\
\text { ciated with what we will call resource posi- } \\
\text { tion barriers" (p. 172) }\end{array}$ & $\begin{array}{l}\text { Posicionamento de recursos como } \\
\text { vantagem competitiva }\end{array}$ \\
\hline R.IV.10 & $\begin{array}{l}\text { "The fact that resource bundles need to be } \\
\text { deployed to achieve or protect such pri- } \\
\text { vileges product market positions is often } \\
\text { overlooked" (p. 1504) }\end{array}$ & $\begin{array}{l}\text { A visão nos recursos é que explica o } \\
\text { posicionamento do produto. }\end{array}$ \\
\hline R.III.21 & $\begin{array}{l}\text { "Those [competencies and resources] which } \\
\text { are distinctive or superior relative to those } \\
\text { of rivals, may become the basis for com- } \\
\text { petitive advantage if they are matched } \\
\text { appropriately to environment opportuni- } \\
\text { ties" (p. 179) }\end{array}$ & $\begin{array}{l}\text { Recursos como fonte de vantagem } \\
\text { competitiva; a vantagem competitiva é } \\
\text { relativa aos concorrentes }\end{array}$ \\
\hline
\end{tabular}

Durante a leitura o pesquisador preocupa-se em identificar temas e conceitos recorrentes em qualquer obra. As palavras em negrito no quadro 4 são termos que foram destacados pelo pesquisador durante a leitura dos textos ou releitura dos quadros gerados. Na interpretação das obras de Porter e TBR foram gerados 66 e 73 protocolos, respectivamente, perfazendo um total de I39. A própria redação das unidades de significado é um ato de interpretação subjetiva do trecho, o que indica não apenas o que o pesquisador entendeu do trecho, mas também permite avaliar quais trechos foram considerados mais relevantes. Os seguintes termos foram destacados na interpretação realizada: indústria/estrutura industrial; ambiente; heterogeneidade/ diferença entre firmas; retornos/ lucratividade/ desempenho; forças 
competitivas; posicionamento; elos/ fit/ ligações/ compatibilidade; recursos/ capacidades/ atividades; firma; valor; concorrentes; combinação de atividades; concorrentes; sustentabilidade; e contexto.

Identificou-se que há uma complementaridade entre as visões, pois foram identificados termos em Porter que primordialmente remetem ao ambiente competitivo da indústria, enquanto que a TBR remete ao desenvolvimento e à sustentação de recursos estratégicos. Entretanto, ambas as perspectivas indicaram termos correlacionados tanto em uma visão interna quanto externa da firma. A tentativa de identificar os termos em comum, ou seja, aquele aspecto invariável do fenômeno nas diferentes visões é obtido pela redução fenomenológica.

\section{Redução Fenomenológica}

Capturar o fenômeno estudado depende do esforço de identificar temas estruturais no decorrer desta codificação e atribuição de significados. Silva (2006) ilustra que a delimitação em temas pode auxiliar como um meio para se chegar à ideia principal; ele pode dar forma ao que não tem forma; pode descrever o conteúdo da ideia; o tema é uma redução da ideia. Essa delimitação de temas consistirá na própria redução fenomenológicatranscedental, pois é fruto de reflexões em que o mundo natural é posto "entre parênteses" e o conteúdo é analisado como puramente dado. Os protocolos codificados são classificados em seus respectivos temas, pelo preenchimento de outro quadro, conforme o Quadro 5. 


\section{Quadro 5 Quadro de Temas}

Tema: Denominação do tema

$\begin{array}{lll}\text { Código } & \text { Unidade de significado } & \text { Temas relacionados } \\ \text { P.O.n } & \begin{array}{l}\text { Descrição do sentido dado pelo autor do } \\ \text { trecho transcrito }\end{array} & \begin{array}{l}\text { Citar os temas que sobrepõe a } \\ \text { este, elucidado pela unidade de } \\ \text { significado. }\end{array}\end{array}$

\section{Ambiente/Estrutura Industrial}

\begin{tabular}{|lll|}
\hline Código & Unidade de significado & Temas relacionados \\
\hline P.I.6 & $\begin{array}{l}\text { Análise da firma em seu ambiente deve ser } \\
\text { relativa e não absoluta. Como o ambiente } \\
\text { é o mesmo, a diferença entre firmas está } \\
\text { nas capacidades em lidar com o ambiente. }\end{array}$ & \\
\hline P.I.7 & $\begin{array}{l}\text { Forças competitivas lidam com o grau } \\
\text { de competitividade, que influencia na } \\
\text { lucratividade a longo prazo. }\end{array}$ & Desempenho \\
\hline
\end{tabular}

\section{Firma}

\begin{tabular}{|c|c|c|}
\hline Código & Unidade de significado & Temas relacionados \\
\hline P.I.3 & $\begin{array}{l}\text { Porter reconhece que a heterogeneidade } \\
\text { entre firmas ocorre pelas diferenças nas } \\
\text { capacidades/atividades }\end{array}$ & Heterogeneidade; atividades \\
\hline P.I.6 & $\begin{array}{l}\text { Análise da firma em seu ambiente deve ser } \\
\text { relativa e não absoluta. Como o ambiente } \\
\text { é o mesmo, as diferenças entre firmas } \\
\text { estão nas capacidades em lidar com o } \\
\text { ambiente. }\end{array}$ & Atividades; ambiente \\
\hline \multicolumn{3}{|c|}{ Criação de Valor } \\
\hline Código & Unidade de significado & Temas relacionados \\
\hline P.1.22 & $\begin{array}{l}\text { Posicionamento maximiza o valor } \\
\text { das capacidades da empresa; } \\
\text { posicionamento é relativo, referência é o } \\
\text { concorrente }\end{array}$ & $\begin{array}{l}\text { Posicionamento; atividade/ } \\
\text { recurso }\end{array}$ \\
\hline P.II.28 & Vantagem competitiva é criação de valor & --- \\
\hline
\end{tabular}

\section{Desempenho Superior}

\begin{tabular}{|lll|}
\hline Código & Unidade de significado & Temas relacionados \\
\hline P.I.2 & $\begin{array}{l}\text { A explicação dos retornos } \\
\text { persistentemente superiores não está } \\
\text { na estrutura industrial, mas sim nas } \\
\text { atividades da empresa. }\end{array}$ & Firma; Atividades \\
\hline P.I.18 & $\begin{array}{l}\text { O posicionamento permite desempenho } \\
\text { superior. }\end{array}$ & Posicionamento \\
\hline
\end{tabular}


Tema: Denominação do tema

\section{Atividades/Recursos/Capacidades}

\begin{tabular}{|lll|}
\hline Código & Unidade de significado & Temas relacionados \\
\hline P.I.3 & $\begin{array}{l}\text { Porter reconhece que a heterogeneidade } \\
\text { entre firmas ocorre pelas diferenças nas } \\
\text { capacidades/atividades }\end{array}$ & Firma; heterogeneidade \\
\hline P.I.6 & $\begin{array}{l}\text { Análise da firma em seu ambiente deve ser } \\
\text { relativa e não absoluta. Como o ambiente }\end{array}$ & \\
& $\begin{array}{l}\text { é o mesmo, as diferenças entre firmas atividades; ambiente } \\
\text { estão nas capacidades em lidar com o } \\
\text { ambiente. }\end{array}$ & \\
\end{tabular}

\section{Heterogeneidade}

\begin{tabular}{|lll|}
\hline Código & Unidade de significado & Temas relacionados \\
\hline P.I.3 & $\begin{array}{l}\text { Porter reconhece que a heterogeneidade } \\
\text { entre firmas ocorre pelas diferenças nas } \\
\text { capacidades/atividades }\end{array}$ & Firma; atividades \\
\hline P.I.6 & $\begin{array}{l}\text { Análise da firma em seu ambiente deve ser } \\
\text { relativa e não absoluta. Como o ambiente } \\
\text { é o mesmo, a diferença entre firmas está } \\
\text { nas capacidades em lidar com o ambiente. }\end{array}$ \\
\hline
\end{tabular}

\section{Posicionamento}

\begin{tabular}{|l|ll|}
\hline Código & Unidade de significado & Temas relacionados \\
\hline P.I.8 & Estratégia é posicionamento & Ambiente \\
\hline P.I.9 & $\begin{array}{l}\text { Finalidade do modelo das } 5 \text { forças } \\
\text { competitivas. Identificar pela análise } \\
\text { do ambiente a posição e possibilidades } \\
\text { estratégicas }\end{array}$ & Ambiente \\
\hline
\end{tabular}

\section{Compatibilidade (Fit)}

\begin{tabular}{|lll|}
\hline Código & Unidade de significado & Temas relacionados \\
\hline P.I.10 & $\begin{array}{l}\text { Existe heterogeneidade entre firmas, } \\
\text { por possuírem capacidades únicas. } \\
\text { Estratégia é o Fit entre forças e fraquezas } \\
\text { e o ambiente. }\end{array}$ & Firma; ambiente \\
\hline P.I.11 & $\begin{array}{l}\text { Finalidade do modelo das } 5 \text { forças } \\
\text { competitivas. Fit entre empresa e } \\
\text { ambiente }\end{array}$ & Firma; ambiente \\
\hline
\end{tabular}


Tema: Denominação do tema

\begin{tabular}{|c|c|c|}
\hline \multicolumn{3}{|c|}{ Compatibilidade (Fit) } \\
\hline Código & Unidade de significado & Temas relacionados \\
\hline P.I.10 & $\begin{array}{l}\text { Existe heterogeneidade entre firmas, por } \\
\text { possuírem capacidades únicas. Estratégia } \\
\text { é o Fit entre forças e fraquezas e o } \\
\text { ambiente. }\end{array}$ & Firma; ambiente \\
\hline P.I.11 & $\begin{array}{l}\text { Finalidade do modelo das } 5 \text { forças } \\
\text { competitivas. Fit entre empresa e } \\
\text { ambiente }\end{array}$ & Firma; ambiente \\
\hline
\end{tabular}

\section{Sustentabilidade}

\begin{tabular}{|lll|}
\hline Código & Unidade de significado & Temas relacionados \\
\hline P.II.31 & $\begin{array}{l}\text { Sustentabilidade da vantagem } \\
\text { competitiva depende de constantes } \\
\text { movimentos estratégicos - alvo móvel }\end{array}$ & Dinâmica \\
\hline P.II.32 & $\begin{array}{l}\text { Sustentabilidade da vantagem } \\
\text { competitiva é ameaçada pelo } \\
\text { concorrente ou pela mudança da } \\
\text { indústria. }\end{array}$ & Dinâmica; ambiente \\
\hline
\end{tabular}

\section{Dinâmica}

\begin{tabular}{|lll|}
\hline Código & $\begin{array}{l}\text { Unidade de significado } \\
\text { P.II.32 }\end{array}$ & $\begin{array}{l}\text { Sustentabilidade da vantagem } \\
\text { competitiva é ameaçada pelo } \\
\text { concorrente ou pela mudança da } \\
\text { indústria. }\end{array}$ \\
\hline P.II.31 & $\begin{array}{l}\text { Sustentabilidade da vantagem } \\
\text { competitiva depende de constantes } \\
\text { movimentos estratégicos - alvo móvel }\end{array}$ & Ambiente \\
\hline
\end{tabular}

Fonte: Elaborado pelos autores com base em Silva (2006).

Nesse ponto do trabalho, o texto em si é deixado de lado e o pesquisador passa a olhar apenas para sua significação das teorias de Estratégia. $\mathrm{O}$ movimento é interior e subjetivo em que as várias partes do todo são unidas e separadas, a fim de identificar quais são aqueles aspectos comuns nas visões analisadas e como esses aspectos podem se encaixar em um todo coerente. Não está sendo feita uma análise quantitativa de frequência ou qualquer artifício, objeto de seleção de fatores, mas há uma análise subjetivamente construída, baseada naquilo que o pesquisador percebe na leitura. Os pressupostos conflitantes entre as duas correntes de pensamento 
são deixados de lado juntamente com o texto em si e o pesquisador encara apenas suas percepções subjetivas da leitura. O processo é intuitivo.

A leitura e interpretação dos protocolos permitiram a identificação de dez temas: (I) Ambiente/Estrutura Industrial; (2) Firma; (3) Criação de valor; (4) Desempenho Superior; (5) Atividades, recursos e capacidades; (6) Heterogeneidade; (7) Posicionamento; (8) Compatibilidade; (9) Sustentabilidade; e (Io) Dinâmica. Além disso, realiza-se a indicação dos temas correlacionados com cada protocolo, o que poderá oferecer caminhos para a análise estrutural do fenômeno.

\section{ANÁLISE ESTRUTURAL DO FENÔMENO}

Com base na análise das várias unidades de significados encontrados para cada tema e das redes de relações existentes entre essas unidades de significados é possível enxergar aquele tema, ou aquele aspecto (parte) do fenômeno, de variadas maneiras, que podem, imaginativamente, combinar diferentes temas e diferentes visões para avaliar diferentes perspectivas da mesma ideia. Esse método de variação imaginativa possibilitará a identificação das características ou do conteúdo invariável do fenômeno, em temas compartilhados ou formas comuns.

Ao fazer uma busca por temas comuns, quase sempre se chega através de temas únicos. [...] Como a análise se desenvolve em seus movimentos para trás e para frente do texto para as afirmações do tema, e o movimento dos temas para dentro da categoria de variação e vice e versa. Como material novo é adicionado, decisões experimentais são alteradas em favor da formulação mais precisa. Não é um processo perfeito, mas é sistemático (BARRIT et al, 2000) .

Os temas são traduzidos em asserções sobre o tema, que são as afirmações feitas pelo pesquisador sobre as unidades de significados que formam aquele tema. As variações, como citado anteriormente, são listadas em separado, constituindo a terceira coluna da análise estrutural. Pela análise do Quadro 6 é possível dar o último passo do processo de análise e interpretação fenomenológica que "é a integração intuitiva das descrições textuais e 
estruturais fundamentais em uma afirmação unificada da essência da experiência do fenômeno como um todo. Essa é a direção-guia das ciências eidéticas, o estabelecimento do conhecimento das essências" (MOUSTAKAs, I994, O. I00). As estruturas do fenômeno são obtidas com base nas unidades de significado conferidas pelo pesquisador e nos temas correlacionados, que subsidiam a variação imaginativa.

\section{Quadro 6 Análise Estrutural do Fenômeno}

\begin{tabular}{|c|c|c|}
\hline Temas & Variações dos temas & Asserçōes sobre o tema \\
\hline $\begin{array}{l}\text { Obtido pelas comparações } \\
\text { entre os diversos temas } \\
\text { identificados e as unidades } \\
\text { de significados dos compo- } \\
\text { nentes dos temas. }\end{array}$ & $\begin{array}{l}\text { As variações são os } \\
\text { temas correlacionados } \\
\text { ao tema principal que } \\
\text { contribuem para o seu } \\
\text { significado. }\end{array}$ & $\begin{array}{l}\text { Afirmações feitas pelo pesquisador sobre as } \\
\text { unidades de significados que formam aquele } \\
\text { tema. }\end{array}$ \\
\hline Ambiente & $\begin{array}{l}\text { Heterogeneidade; e } \\
\text { Compatibilidade. }\end{array}$ & $\begin{array}{l}\text { O ambiente é formado por uma multipli- } \\
\text { cidade de atores, por outras empresas for- } \\
\text { necedoras, concorrentes, canais, entrantes } \\
\text { potenciais, substitutos, compradores, entre } \\
\text { outros. Cada um desses atores possui dife- } \\
\text { renciações, formando uma heterogenei- } \\
\text { dade que possibilita inúmeras formas de } \\
\text { compatibilidades. }\end{array}$ \\
\hline Firma & $\begin{array}{l}\text { Atividades/Recursos; } \\
\text { Heterogeneidade; e } \\
\text { Compatibilidade. }\end{array}$ & $\begin{array}{l}\text { A firma é um conjunto idiossincrático de } \\
\text { recursos e as diferentes possibilidades de } \\
\text { combinações formam a heterogeneidade } \\
\text { entre firmas. As firmas buscam a compa- } \\
\text { tibilização interna de suas atividades e a } \\
\text { compatibilização externa de suas ativida- } \\
\text { des, com as atividades desenvolvidas pelos } \\
\text { atores integrantes de seu ambiente com- } \\
\text { petitivo. }\end{array}$ \\
\hline Compatibilidade & $\begin{array}{l}\text { Atividades/Recursos; } \\
\text { Heterogeneidade; e } \\
\text { Posições }\end{array}$ & $\begin{array}{l}\text { A heterogeneidade das firmas, do ambiente, } \\
\text { dos compradores permite a disponibiliza- } \\
\text { ção de um feixe de possibilidades de com- } \\
\text { patibilidade e a estratégia é a escolha e/ou } \\
\text { desenvolvimento dessa compatibilidade }\end{array}$ \\
\hline
\end{tabular}




\begin{tabular}{|c|c|c|}
\hline Temas & Variações dos temas & Asserções sobre o tema \\
\hline $\begin{array}{l}\text { Posicionamento } \\
\text { Sustentável }\end{array}$ & $\begin{array}{l}\text { Criação de Valor; } \\
\text { Sustentabilidade; } \\
\text { Dinâmica }\end{array}$ & $\begin{array}{l}\text { A compatibilidade entre atividades forma o } \\
\text { posicionamento competitivo das empresas, } \\
\text { pois marca sua posição de atividades em } \\
\text { relação a cada um dos atores integrantes } \\
\text { dos ambientes. As mudanças ambientais } \\
\text { e das atividades permitem a sustentabili- } \\
\text { dade da vantagem ou pelo impedimento } \\
\text { de reprodução ou evitando a obsolescência } \\
\text { da vantagem. }\end{array}$ \\
\hline Desempenho Superior & Criação de Valor & $\begin{array}{l}\text { A posição estratégica permite a criação de } \\
\text { valor distintivo para o consumidor, ofere- } \\
\text { cendo a geração de desempenhos supe- } \\
\text { riores. }\end{array}$ \\
\hline
\end{tabular}

O Quadro 6 apresenta a análise estrutural final do fenômeno, sendo a primeira coluna a indicação dos temas compartilhados.

A interpretação geral dos textos da Administração Estratégica pode ser descrita como segue: a heterogeneidade existe tanto do lado da oferta (entre empresas) quanto do lado da demanda (indivíduos e famílias ou outras empresas). A firma é formada por uma combinação idiossincrática de atividades que são internamente compatíveis. O ambiente é formado por firmas e famílias que possuem atividades internamente compatíveis. As atividades internas da firma se ligam ao ambiente quando há atividades entre os atores que formam o ambiente.

$\mathrm{O}$ alinhamento entre as atividades internas e externas da firma formam a compatibilidade ou a adequação entre firma e ambiente, refletida em um posicionamento. $\mathrm{O}$ posicionamento, portanto, é resultado das atividades da empresa e das atividades relativas aos atores integrantes do ambiente. A aquisição, reprodução ou substituição das atividades ou da forma que as atividades são combinadas proporcionará a sustentabilidade da posição ocupada. Além disso, as mudanças no ambiente e nas atividades da empresa também contribuem para a sustentabilidade do posicionamento da empresa.

Como resultado geral do posicionamento, a empresa obtém desempenhos superiores, pois a compatibilidade entre atividades internas e externas da firma formam um conjunto que é capaz de criar valor para o consumidor e, ao mesmo tempo, não pode ser copiado ou substituído pelo concorrente, 
pois é uma posição única. A Figura I apresenta os cinco elementos da estrutura essencial da vantagem competitiva e suas relações.

Figura 1 Estruturas essenciais da vantagem competitiva

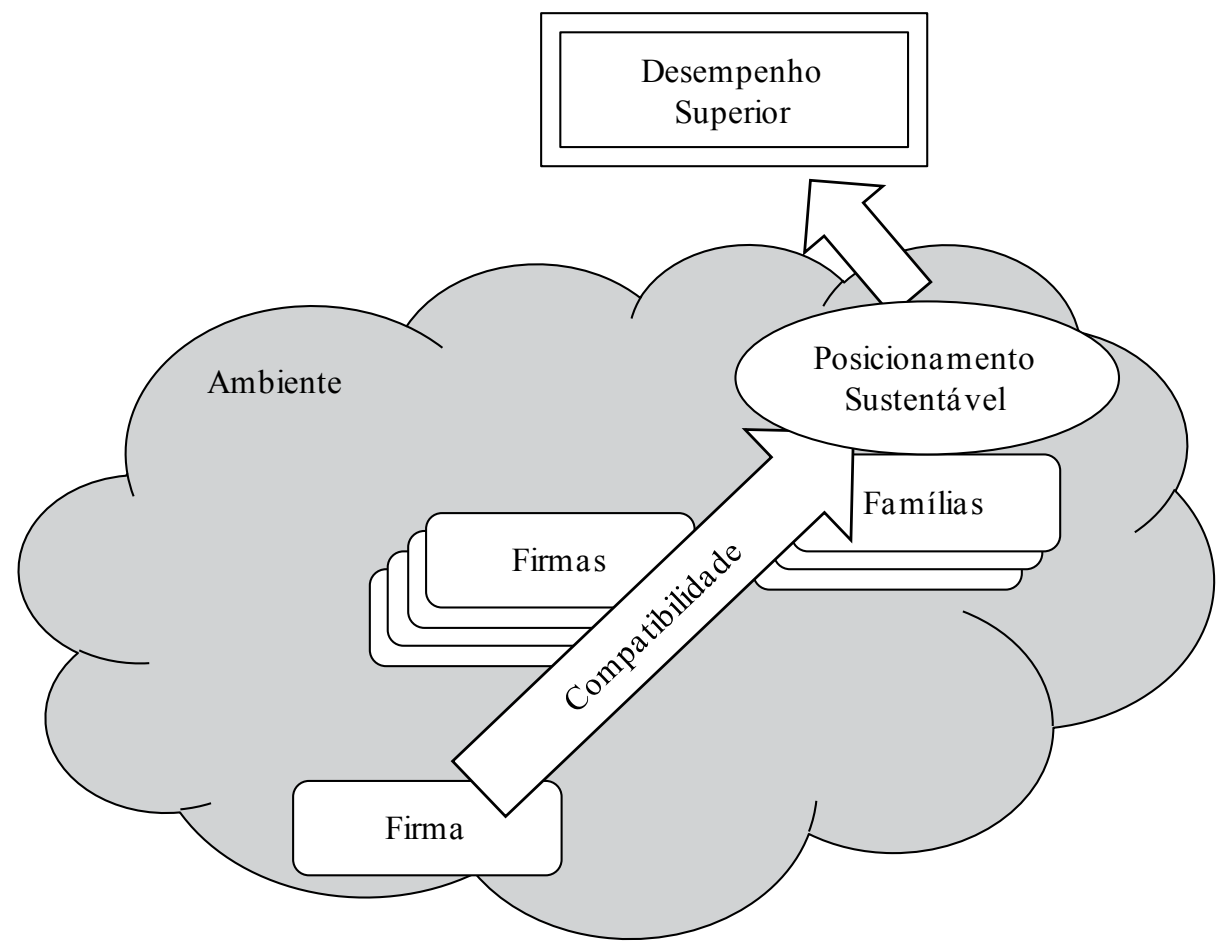

Este é um conhecimento puro, um conhecimento das essências. Não há uma fundamentação teórica ou não há a consideração de pressupostos na análise. A análise a priori realizada baseia-se numa situação inicial em que o intérprete (autor) se abstém de pré-concepções, teorias ou observações da realidade, examinando o que não varia ao considerar diferentes perspectivas da vantagem competitiva. Este pode ser um fio condutor para o desenvolvimento de uma pesquisa.

Com isto, é possível identificar o conhecimento a priori, que poderá constituir um fio condutor para o desenvolvimento da pesquisa. Caso seja necessário o pesquisador apresentar um relatório da pesquisa ou ele sinta 
necessidade de fazê-lo, algumas orientações podem ser seguidas: como Gadamer afirmou um ser pode ser compreendido pela linguagem, ou seja, o autor ao elaborar um relatório fenomenológico produz mais que um texto, produz a si próprio. O produto desta pesquisa não deve ser mera descrição, mas sim um texto carregado de interpretação.

É importante sempre manter forte ligação entre as partes e o todo; entre os temas compartilhados e a síntese intuitiva da integração das várias partes do fenômeno. A redação de textos é um processo de reflexão e também uma atividade de escrita reescrita. É um percurso que envolve muitas idas e vindas aos protocolos [...] e aos quadros temáticos, observando a ligação entre a parte e o todo que reflete (sILVA, 2006, p. 290).

Este conhecimento obtido pela hermenêutica fenomenológica não precisa ter um fim em si mesmo, mas pode constituir um passo inicial de uma pesquisa empírica ou teórica. O que se quer dizer é que esse pode ser um exercício de posicionamento do autor que precede sua pesquisa ou pode ser uma pesquisa em si, em que o resultado final é um ensaio sobre a interpretação dos textos lidos. De uma forma ou de outra, procura-se oferecer um método de interpretação para textos organizacionais. 


\section{CONSIDERAÇÕES FINAIS}

O campo dos Estudos Organizacionais é fragmentado, dicotômico e plural, o que dificulta a conversação entre teorias ao se deparar com a diversidade de pressupostos e princípios. A proposta do artigo, portanto, é oferecer um framework com princípios e tarefas para uma hermenêutica fenomenológica, buscando as características estruturais essenciais de determinado objeto de estudo. Essa é uma ferramenta que se distingue da abordagem fenomenológica de uma pesquisa empírica. Essa distinção é esclarecida pelo objeto de análise: por um lado, a pesquisa empírica estuda a realidade concreta e, por outro lado, a hermenêutica fenomenológica trata da interpretação de textos, ou seja, das ideias, conceitos e teorias no texto. A hermenêutica fenomenológica, portanto, não trata de uma visão de mundo por uma lente fenomenológica, mas da aquisição de um significado fundamentado na interpretação do pesquisador.

Assim, como limitação do método proposto, destaca-se que o resultado da interpretação refere-se, na verdade, a percepções subjetivas do pesquisador em relação à sua leitura do texto. Esse é um processo de constante posicionamento do autor sobre cada aspecto relevante do fenômeno. Durante a redação do texto, é necessário deixar explícito seu "ponto de partida" e seus caminhos na obtenção das interpretações, a fim de esclarecer ao leitor o modo de obtenção de suas conclusões. Ademais, esse é um procedimento que pode ser muito mais propedêutico do que uma pesquisa final de um assunto. Do ponto de vista metodológico, no campo da Estratégia, por exemplo, pesquisas que reúnem opiniões de especialistas (NAG; HAMBRICK; CHEN, 2007) podem oferecer visões mais objetivas que a análise fenomenológica do texto. Entretanto, a percepção subjetiva do autor na análise contribui para a identificação de lacunas teóricas e a identificação de potenciais avanços teóricos 


\section{REFERÊNCIAS}

ABBAGNANO, N. Dicionário de filosofia. São Paulo: Martins Fontes, 2007.

BAIN, J. S. Industrial organization. New York: John Wiley \& Sons, 1965.

BARRIT, L.; BEEKMAN, T.; BLEEKER, H.; MULDERIJ, K. Analyzing

phenomenological descriptions. Phenomenology + Pedagogy, v. 2, n. 1, p. 1-17, 2000.

BARNEY, J. B. Firms resources and sustained competitive advantage. Journal of Management, v. 17, n. 1, p. 99-120, 1991.

BURREL, G.; MORGAN, G. Sociological paradigms and organizational analysis: elements of the sociology of corporate life. London: Heinemann Educational Books, 1979.

DIERICKX, I.; COOL, K. Asset stock accumulation and sustainability of competitive advantage. Management Science, v. 35, n. 12, p. 1504-1511, 1989.

FAIRCLOUGH, N. Discourse and social change. Cambridge: Polity Press, 1992.

GODOI, C. K. Perspectivas de análise do discurso nos estudos organizacionais. In:

GODOI, C.; BANDEIRA-DE-MELO, R.; SILVA, A (Org.). Pesquisa qualitativa em estudos organizacionais: paradigmas, estratégias e métodos. São Paulo: Saraiva, 2006.

HEIDEGGER, M. Ser e tempo: Parte I. Petrópolis: Editora Vozes, 1986.

HISTÓRIA DA FILOSOFIA. A filosofia de Kant a Husserl, v. 3. Lisboa: Dom Quixote, 1981.

HUSSERL, E. The shorter logical investigation. New York: Routledge, 2002.

KUHN, T. S. A estrutura das revoluções científicas. São Paulo: Editora Perspectiva, 2000.

LIPPMAN, S. A.; RUMELT, R. P. Uncertain imitability: an analysis of interfirm

differences in efficiency under competition. The Bell Journal of Economics, v.13, n. 2, p. 418-438, 1982.

MASON, E. S. Price Production Policies of Large-Scale Enterprise. American Economic Review, v.29, n.1, p.64-71, 1939.

MOREIRA, D. A. O método fenomenológico na pesquisa. São Paulo: Thomson Pioneira, 2002.

MOUSTAKAS, C. Phenomenological Research Methods. Thousand Oaks: Sage, 1994.

NAG, R.; HAMBRICK, D. C.; CHEN, M. What is strategic management really? Inductive derivation of a consensus definition of the field. Strategic Management Journal, v. 28, n.9, p. 935-955, 2007.

NERUR, S. P.; RASHEED, A. A.; NATARAJAN, V. the intellectual structure of the strategic management field: an author co-citation analysis. Strategic Management Journal, v. 29, n. 3, p. 319-336, 2008.

PALMER, R. E. Hermenêutica. Lisboa: Edições 70, 1997.

PENROSE, E. The theory of growth of the firm. New York: Wiley, 1959. 
PETERAF, M. A. The cornerstone of competitive advantage: a resource based view. Strategic Management Journal, v.14, n. 3, p. 179-191, 1993.

PORTER, M. E. Competitive Strategy. New York: Free Press, 1980.

PORTER, M. E. Competitive Advantage. New York: Free Press, 1985.

PORTER, M. E. What is strategy? Harvard Business Review, v. 74, n. 6, p. 61-78, 1996.

RAMOS-RODRÍGUEZ, A. R.; RUÍZ-NAVARRO, J. Changes in the intellectual structure of strategic management research: a bibliometric study of the Strategic Management Journal, 1980-2000. Strategic Management Journal, v. 25, n. 10, p. 981-1004, 2004.

RUMELT, R. P. Towards a strategic theory of the firm. In: LAMB, R. B. Competitive Strategic Management. Prentice Hall: Englewood Cliffs, 1984.

SILVA, A. B. A fenomenologia como método de pesquisa em estudos organizacionais. In: GODOI, C. K.; BANDEIRA-DE-MELO, R.; SILVA, A. B (Org.). Pesquisa qualitativa em estudos organizacionais: paradigmas, estratégias e métodos. São Paulo: Saraiva, 2006.

SPAREMBERGER, R. F. L. Betti x Gadamer: da Hermenêutica objetivista à hermenêutica criativa. Revista da Faculdade de Direito da Universidade Federal do Paraná, v. 39, 2003.

TEECE, D. J.; PISANO, G.; SHUEN, A. Dynamic Capabilities and Strategic Management. Strategic Management Journal, v. 18, n. 7, p. 509-533, 1997.

VRIES, M. F. R. K.; MILLER, D. Interpreting organizational texts. Journal of Management Studies, v. 24, n. 3, p. 504-511, 1987.

WERNERFELT, B. A resource-based view of the firm. Strategic Management Journal, v. 5, n.2, p. 171-180, 1984. 
1 "The possible range of choice is indeed so large that what is regarded as science by traditional scientist covers but a small range of options" (BURREAL; MORGAN, 1979, p. 2)

2 Geisteswissenschaften: "quer dizer todas as humanidades e as ciências sociais, todas as disciplinas que interpretam as expressões da vida interior do homem, quer essas expressões sejam gestos, actos históricos, leis codificadas, obras de arte ou de literatura" (PALMER, 1997, p. 105).

3 Quiididade: “Termo introduzido pelas traduções latinas feitas no século xII (do árabe, com base nas obras de Aristóteles; corresponde à expressão aristotélica [...] (quod quid erat esse) [aquilo em virtude do que alguma coisa é o que é]. Esse termo significa essência necessária (substancial) ou substância” (ABBAGNANO, 2007, p. 960).

4 Pre-sença: "Esse ente que cada um de nós somos e que, entre outras, possui em seu ser a possibilidade de questionar, nós o designamos com o termo pre-sença" (HEIDEG GER, 1986, p. 33) [...]. "não é sinônimo nem de homem, nem de ser humano, nem de humanidade, embora conserve uma relação estrutural. Evoca o processo de constituição ontológica de homem, ser humano e humanidade. É na pre-sença que o homem constrói o seu modo de ser, a sua existência, a sua história etc. (HEIDEGGER, 1986, p.309)

5 "Husserl [...] contrasted the phenomenological universal Epoche with Cartesian doubt. The phenomenological Epoche does not eliminate everything [...]. What is doubted are the scientific "facts", the knowing of things in advance, from a external base rather than from internal reflection and meaning" (MOUSTAKAs, 1994, p. 85).

6 "Epoche includes entering a pure internal place, as an open self, ready to embrace life in what it truly offers. From the Epoche, we are challenged to create new ideas, new feelings, new awareness and understandings. We are challenged to come to know things with a receptiveness and a presence that lets us be and lets situations and things be, so that we can come to know them just as they appear to us" (MOUSTAKAs, 1994).

7 "It is called transcendental because it moves beyond the everyday to the pure ego in which everything is perceived freshly, as if for the first time (MOUstakas, 1994, p. 34). "It is called 'phenomenological' because it transforms the world into mere phenomena. It is called 'reduction' because it leads us back (Lat reducere) to the source of the meaning and existence of the experienced world" (Schmitt apud MOUSTAKAs, 1994, p. 34, itálico no original).

8 "Imaginative Variation enables the researcher to derive structural themes from the textural descriptions that have been obtained through Phenomelogical Reduction” (MOUstakas, 1994, p. 99).

9 De acordo com Barney (1991), os modelos de Porter utilizam os pressupostos de homogeneidade entre firmas e mobilidade perfeita de recursos, enquanto que a TBR emprega a heterogeneidade entre firmas e a mobilidade imperfeita de recursos.

10 "In making a search for common themes one almost always comes across unique themes. [...] As the analysis goes on there is a continual movement back and forth from text to theme statements, and movement of themes into the variation category or vice versa. As new material is added, original, tentative decisions are changed in favor of more accurate formulation. It isn't a flawless procedure but it is systematic" (BARRIT et al., 2000).

11 "Is the intuitive integration of the fundamental textural and structural descriptions into a unified statement of the essences of the experience of the phenomenon as a whole. This is the guiding direction of the eidetic sciences, the establishments of knowledge of essences" (MOUSTAKAs, 1994, p. 100). 


\section{DADOS DOS AUTORES}

NOBUIUKI COSTA ITO^ nobuiuki@usp.br

Doutorando em Administração pela FEA/USP

Instituição de vinculação: Universidade de São Paulo São Paulo/SP - Brasil

Áreas de interesse em pesquisa: Estratégia, Direito, Economia e Organizações.

${ }^{\star}$ Av. Prof. Luciano Gualberto, 908, Sala C-18

Cidade Universitária São Paulo/SP 05508-900

FERNANDO ANTONIO PRADO GIMENEZ fapgimenez2009@hotmail.com

Doutor em Administração pela University of Manchester

Instituição de vinculação: Universidade Federal do Paraná Curitiba/PR - Brasil

Áreas de interesse em pesquisa: Estratégia, estratégia em pequenas empresas e empreendedorismo. 